\title{
El paso interoceánico por el istmo de Tehuantepec, 1847-1855. Una idea británica de las relaciones México-Estados Unidos
}

\author{
Samantha Álvarez Macotela \\ INSTITUTO MORA
}

El objetivo de este artículo es presentar las reflexiones que arroja la revisión de la correspondencia de Percy William Doyle, encargado de negocios y ministro plenipotenciario de Gran Bretaña en México, con el Foreign Office, relativa al paso por el istmo de Tehuantepec, durante los años arriba señalados, en el contexto de las relaciones México-Estados Unidos.

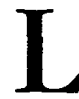

a relevancia del asunto del paso interoceánico por el istmo de Tehuantepec dentro el estudio de las relaciones México-Estados Unidos a mediados del siglo XIX jamás ha estado en entredicho: el tema ha atraído la atención de diversos estudiosos, desde la época de los sucesos hasta el día de hoy. Así pues, la posibilidad de aproximación al mismo con la esperanza de obtener conclusiones novedosas se basa en el uso de fuentes alternativas y en la formulación de preguntas guía diferentes de las tradicionales. Nuestra fuente principal son los materiales del Ministerio de Asuntos Exteriores de
Gran Bretaña, Foreign Office, dejando a un lado los documentos de los Archivos Nacionales de Washington y del Archivo Histórico Diplomático de la Secretaría de Relaciones Exteriores, desde luego más socorridos. En cuanto a las preguntas, algunas de ellas son: ¿cuál era la preocupación central de la política exterior británica hacia México?, equé papel jugaron Percy William Doyle y la cuestión de Tehuantepec en la misma?, ¿qué representaba Doyle dentro de la política exterior británica?, equé representaba Méxi$c o$ ?, èen qué medida la preocupación por Estados Unidos moldeó la política exterior británica hacia nuestro país? 
El objetivo de este artículo es presentar las reflexiones que arroja la revisión de la correspondencia de Doyle, encargado de negocios y ministro de Gran Bretaña en México, con el Foreign Office, relativa al paso por el istmo de Tehuantepec, durante los años señalados.

Doyle llegó a México por primera vez como encargado de negocios en 1843; regresó a fines de 1847 y más tarde recibió el nombramiento de ministro plenipotenciario, mismo que mantuvo hasta 1858 , aunque dejó su puesto en 1855. Cabe mencionar que, pese al importante papel que desempeñó en nuestro país, su figura ha pasado prácticamente inadvertida en la historiografía, tanto mexicana como británica y estadunidense. Este ensayo pretende rescatar al diplomático como actor de peso dentro de la política exterior mexicana del siglo XIX; vale mencionar que otro estudio interesante sería el de su participación en la política interior de nuestro país.

Tres son las grandes materias que surgen del análisis propuesto. Una se refiere al papel de Gran Bretaña como potencia mundial, a sus intereses comerciales y políticos, la defensa de sus súbditos en el extranjero y el equilibrio de poder en el continente americano. ${ }^{1}$ Otro asunto clave es la visión que Doy. le tenía de la política interna mexicana; este personaje hacía gala constantemente de sus conocimientos sobre los actores, los intereses y la manera en

\footnotetext{
${ }^{1}$ Bourne, Britain, 1967; Clarke, British, 1989, pp. 216-257; Kennedy, Realities, 1981, pp. 17-73; Jones, American, 1974.
}

que se conducía el país. ${ }^{2}$ El tercer tema son las opiniones británicas -las personales de Doyle y las oficiales de su gobierno- sobre Estados Unidos y los estadunidenses en relación con el proyecto transístmico; éste es el que desarrollamos a continuación.

\section{LOS DIPLOMÁTICOS ANGLOSAJONES EN MÉXICO}

Las diferencias, rivalidades y malentendidos entre británicos y estadunidenses son lugares comunes de la historia. El presente caso permite analizar ejem. plos concretos de prejuicios y desconfianza, lo mismo que descubre vínculos de amistad y cooperación que ocurrieron en nuestro país al relacionarse los enviados de cada nación entre sí.

Desde mediados de la década de 1840 eran constantes los roces entre Estados Unidos y Gran Bretaña respecto a la búsqueda y el control de posibles rutas interoceánicas. La solución fue el tratado Clayton-Bulwer, que se

\footnotetext{
${ }^{2}$ En este sentido, y durante su segunda gestión en México, Doyle no fue el típico diplomático inglés del que habló hace unos años el investigador John Mayo: poco diestro, falto de conocimiento sobre su lugar de destino, de reacciones impacientes y exageradas. Sin embargo, para crédito de este autor, hay que reconocer que la primera estancia de Doyle en tierras mexicanas fue desastrosa, en gran medida por su inexperiencia y precipitación; el infame caso de la bandera británica exhibida como trofeo de guerra en el Palacio Nacional es un tema digno de trabajarse: pese a su aspecto anecdótico puede arrojar luz sobre el carácter de las relaciones México-Gran Bretaña durante la primera mitad del siglo XIX. Véase Mayo, "Impatient", 1983, p. 199.
} 


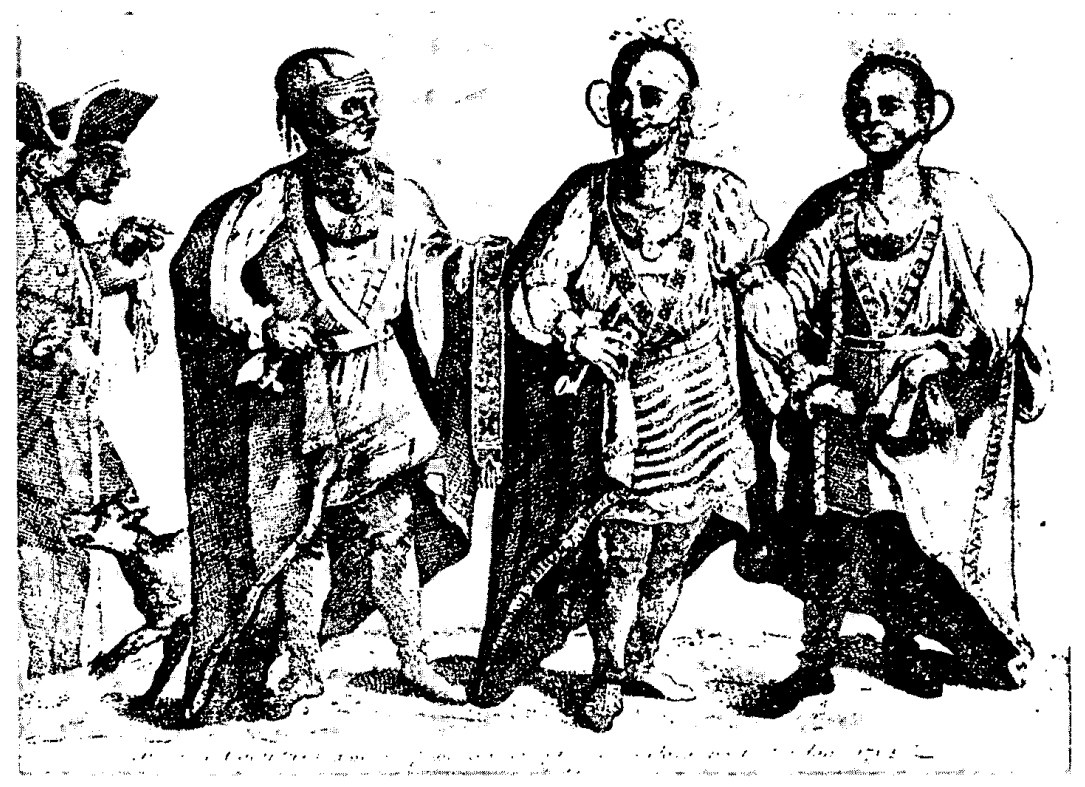

firmó el 19 de abril de 1850 , y en el que ambas partes se comprometieron a impulsar la construcción de un canal, garantizar su neutralidad, declinar privilegios exclusivos y abstenerse de colonizar o dominar región centroamericana alguna. ${ }^{3}$

Pero aquel pacto no evitó las suspicacias. Una muestra se observó cuando José María Lacunza, el ministro de Relaciones, pidió a Doyle su opinión sobre la posibilidad de que, una vez que funcionara el paso interoceánico por Tehuantepec, las embarcaciones con bandera mexicana pudieran gozar de

\footnotetext{
${ }^{3}$ Bourne, Britain, 1967, pp. 170-205. Jones, American, 1974, pp. 77-98.
}

aranceles preferentes; el británico respondió que ello se prestaría a fraudes, en especial por parte de los estadunidenses, quienes no dudarían en hacer uso fraudulento de la enseña nacional. ${ }^{4}$ Cabe preguntarse por qué sólo se sospechaba de los estadunidenses y por qué los comerciantes de otras nacionalidades serían menos proclives al uso de un subterfugio tan sencillo

\footnotetext{
${ }^{4}$ Doyle a Palmerston [Henry John Temple], México, 16 de marzo de 1850 , despacho núm. 26 en Great Britain Public Record Office, MP1934, General Correspondence, Foreign Office Papers/50, rollo 100 , vol. 235 , f. 172 , liste material se encuentra en la Biblioteca Daniel Cosío Villegas, de El Colegio de México; en adelante $\mathrm{FO} / 50$ ]
} 
como eficaz. Otro comentario por el estilo se refiere a la necesidad y conveniencia de nombrar cónsules en zonas estratégicas del istmo, con el objetivo de vigilar los movimientos de los estaunidenses en México. ${ }^{5}$

Pese a los recelos, era inevitable el trato cercano entre los diplomáticos extranjeros, especialmente aquellos de origen anglosajón. Doyle compartió su gestión con varios enviados estaunidenses, entre quienes destacan -para la cuestión del istmo- Robert P. Letcher, William Conkling y James M. Gadsden. Con ellos le tocó ser, de algún modo, anfitrión en el país, debido quizá al hecho de conocer mejor a los mexicanos y sus asuntos; incluso llegó a servir de traductor e intérprete-sobre todo a Conkling, quien no hablaba español-, ${ }^{6}$ lo cual puede dar una idea de la influencia personal del británico.

Cuando Letcher llegó a México, Doyle -quien lo conocía desde sus tiempos de agregado en la legación británica en Washington- ${ }^{7}$ advirtió sus escasas nociones sobre el país, su intranquilidad por la ayuda británica en la formulación de propuestas para el paso interoceánico y, en general, su malestar respecto al cariz que el negocio tomaba por entonces. ${ }^{8}$ Un año y medio después,

\footnotetext{
${ }^{5}$ Doyle a Palmerston, México, 8 de febrero de 1851 , despacho núm. 17, FO/50, rollo 103 , vol. 143, fs. 121-122.

${ }^{6}$ Doyle a lord John Russell, México, 4 de marzo de 1853 , despacho núm. $35, \mathrm{FO} / 50$, rollo 110, vol. 259, f. 29.

${ }^{7}$ Doyle a Palmerston, México, 4 de noviem. bre de 1851, despacho núm. 95, FO/50, rollo 104 , vol. 246 , f. 181.

'Doyle a Palmerston, México, 13 de abril de 1850 , despacho núm. 31, FO/50, rollo 100 , vol. 236, fs. 229-230.
}

Doyle podía preciarse de su intimidad con Letcher y de la importancia que éste concedía a sus opiniones. ${ }^{9}$ Para 1852, el ministro británico achacaba el estancamiento de las negociaciones de la vía transístmica a la frivolidad de Letcher, su pretensión de ganar tiempo a toda costa, sus intrigas y aun las calumnias que había instigado y que lastimaban la persona de José Fernando Ramírez, entonces ministro de Relaciones y con quien Doyle simpatizaba, como se advierte en distintos despachos. ${ }^{10}$

Similares fueron sus reacciones ante James Gadsden. A fines de 1853, el inglés declaró la desconfianza que sentía debido a las diferencias entre el discurso del enviado estaunidense y el del secretario de Estado, William L. Marcy; en su opinión era evidente que Gadsden pretendía amenazar e intimidar a México con tal de conseguir sus objetivos, incluso pasando por encima de las instrucciones de su gobierno. ${ }^{11}$ Más adelante, Doyle destacó la hostilidad del estaunidense hacia Europa -especialmente hacia Gran Bretaña- por su

\footnotetext{
${ }^{9}$ Doyle a Palmerston, México, 4 de noviembre de 1851 , despacho núm. $95, \mathrm{FO} / 50$, rollo 104 , vol. 246, f. 181.

${ }^{10}$ Ibid., f. 183 y 4 de enero de 1852 , despacho núm. 5, rollo 106, vol. 251, fs. 47.49; Doyle a lord Granville [George Leveson-Gower], México, 4 de abril de 1852, despacho confidencial núm. 17, rollo 106, vol. 251, fs. 297-298; Doyle a lord Malmesbury [James Harris], México, 5 de mayo de 1852, despacho confidencial núm. 31, FO/50, rollo 106 , vol. 252 , fs. $9-19$, y 2 de septiembre de 1852, despacho núm. 65, FO/50, rollo 107 , vol. 253 , fs. $175-181$.

"Doyle a lord Clarendon [George Frede. rick Villiers], México, 3 de diciembre de 1853, despacho secreto núm. $117, \mathrm{FO} / 50$, rollo 111 , vol. 261, fs. 273-275.
} 
predominio en México, que juzgaba adverso a los intereses de su país. ${ }^{12}$

Resulta provechoso considerar las opiniones anteriores dentro del marco de uno de los temas polémicos de las relaciones Estados Unidos-Gran Bretana: en general se reconoce que, para la época que nos ocupa, la nación europea había cambiado sus perspectivas imperiales, preocupándose más por sus intereses comerciales que por los territoriales, y se comenta que durante este periodo los estaunidenses reaccionaban con exceso ante la influencia inglesa. ${ }^{13}$ Sin embargo existe otra corriente de opinión que cuestiona el mito del pretendido desinterés colonial británico durante el siglo XIX, y que justifica ampliamente los recelos estadunidenses. ${ }^{14}$

En su extensa obra acerca de algunos aspectos económicos de la política exterior británica, D. C. M. Platt estableció que las bases de aquélla, respecto a América Latina, fueron el comercio y las inversiones. ${ }^{15}$ Inglaterra se contentaba con gozar de las mismas ventajas que otros países y no pretendía privilegios exclusivos; ello podía obtenerlo sin recurrir a presiones diplomáticas desmesuradas y, desde luego, sin pen. sar siquiera en acciones bélicas. ${ }^{16}$

De acuerdo con lo que hemos investigado respecto a Percy Doyle, es posible afirmar que la reserva de los estadu-

${ }^{12}$ Doyle a Clarendon, México, 18 de diciembre de 1853, despacho secreto núm. 120, FO/50, rollo 111 , vol. 261 , f. 306 .

${ }^{13}$ Gallagher y Robinson, "Imperialism", 1953, pp. 1-15.

${ }^{14}$ Brauer, "United", 1988, pp. 19-37.

${ }^{15}$ Platt, Finance, 1971, p. 312.

${ }^{16} \mathrm{Ibid}$., pp. 316-331. nidenses estaba justificada. Aunque el diplomático no se permitiera expresar. lo abiertamente, en su correspondencia queda claro que la Gran Bretaña haría lo posible por estorbar el avance de Estados Unidos sobre México, aprovechando y fomentando al mismo tiempo las desavenencias entre ambos países en beneficio propio. Todo esto dentro de los cánones diplomáticos.

\section{LAS MIRAS AVIESAS DE ESTADOS UNIDOS}

Para Doyle fue evidente, muy pronto, que los estaunidenses tenían los ojos puestos en la región del istmo, estratégica y potencialmente rica. Más allá del establecimiento de una vía de comunicación -que él reconocía como importante para el desarrollo del Oeste, con el oro recién descubierto y las posibilidades comerciales con el Lejano Oriente, en franca competencia con los intereses británicos-, el diplomático afirmaba que Estados Unidos estaba decidido a establecerse en la zona, a tomar posesión e incluso a introducir esclavos en la misma. ${ }^{17} \mathrm{El}$ fantasma de Texas se cernía sobre Tehuantepec con claridad meridiana, según Doyle, quien así lo indicó constantemente en sus despachos, haciendo eco de las preocupaciones de políticos como Mariano

${ }^{17}$ Doyle a Palmerston, México, 24 de diciembre de 1847 , despacho duplicado núm. $7, \mathrm{FO} /$ 50 , rollo 89 , vol. 212 , f. 238,14 de julio de 1850 , despacho núm. $24, \mathrm{FO} / 50$, rollo 100 , vol 237 , f. 63, y 4 de junio de 1851, despacho núm. 51, FO/50, rollo 103, vol. 244, f. 237; Doyle a Malmesbury, México, 3 de octubre de 1852, des. pacho núm. 71, FO/50, rollo 107 , vol. 253 , f. 235. 
Yáñez y el mismo José Fernando Ramírez. ${ }^{18}$ Por convicción, por conveniencia propia o por ambos motivos, el inglés resaltaba las intenciones colonizadoras de los vecinos del norte, usando con frecuencia las palabras ominosas "otro Texas", para horror de sus interlocutores mexicanos.

A esto se agrega la preocupación por la actividad de los especuladores y su influencia en el asunto del paso interoceánico. Los materiales del Foreign Office muestran claramente que Percy Doyle estaba convencido de la fuerza de aquellos "inversionistas" de Estados Unidos, por desgracia anónimos en sus despachos. Ya desde mediados de 1848, el Consejo de Comercio británico se preguntaba, con base en los informes del entonces encargado de negocios en México, si Estados Unidos de verdad tenía la intención de construir una vía de comunicación de tan elevado costo. ${ }^{19}$ Doyle acusó a Letcher, en 1852 , de proteger abiertamente los intereses de los especuladores, incluso pasando por encima de la llamada Compañía de Nueva Orleans y de los deseos de su gobierno; ${ }^{20}$ acusó, sin nombrarlos, a algunos políticos mexicanos, quienes

\footnotetext{
${ }^{18}$ Doyle a Palmerston, México, 4 de abril de 1851, despacho núm. 50, FO/50, rollo 103 , vol. 143 , f. 240,5 de julio de 1851 , despacho núm. 57 , FO/50, rollo 103 , vol. 245 , f. 8 , y 4 de agosto de 1851 , despacho privado s.n., FO/50, rollo 104, vol. 245, fs. 226-227; Doyle a Malmesbury, México, 3 de octubre de 1852, despacho núm. 71 , FO/50, rollo 107 , vol. 253 , f. 235.

${ }^{19}$ G. R. Porter a [e?] Eddisbury [Londres], 12 de agosto de 1848, FO/50, rollo 95 , vol. 225, f. 205.

${ }^{20}$ Doyle a Palmerston, México, 4 de enero de 1852 , despacho núm. 5 , FO/50, rollo 106 , vol. 251 , f. 54 .
}

con falsos discursos patrióticos sólo esperaban obtener beneficios personales. ${ }^{21}$ Incluso, cuando se trató la posibilidad de otorgar privilegios para construir vías férreas en distintos lugares del país, en 1853 y 1855 , Doyle alertó al gobierno mexicano sobre el peligro de que usureros estaunidenses se inmiscuyeran con éxito en alguna licitación, con fines especulativos, transformándola así en "otro Tehuantepec". ${ }^{22}$

Es pertinente aclarar que Doyle, con sus conocimientos sobre Estados Unidos y su política interna, era consciente de la diferencia entre la posición oficial del gobierno y los particulares representados por diversas compañías. ${ }^{23}$ Como se dijo arriba, uno de los cargos del inglés en contra de Letcher era que éste cuidaba con mayor ahínco los intereses privados que los oficiales, como era su deber. ${ }^{24}$ Pero, al final, el pensamiento de Doyle sobre este punto se reducía a la idea de que Estados Unidos -mediante su gobierno o sus ciudadanos- iba en pos de Tehuantepec.

${ }^{21}$ Doyle a Malmesbury, México, 2 de septiembre de 1852, despacho núm. 65, f. 176.

${ }^{22}$ Sobre el ferrocarril México-Veracruz, véase Doyle a Clarendon, México, 3 de diciembre de 1853 , despacho núm. 114, FO/50, rollo 111 , vol. 261 , f. 242 ; sobre la vía en el norte, véase Doyle a Clarendon, México, 7 de febrero de 1855 , despacho núm. $20, \mathrm{FO} / 50$, rollo 118 , vol. 276, fs. 178-179.

${ }^{23}$ Doyle a Palmerston, México, 4 de agosto de 1851 , despacho núm. 66, FO/50, rollo 103 , vol. 245 , f. 166

${ }^{24}$ Doyle a Palmerston, México, 4 de febrero de 1852, despacho núm. $7, \mathrm{FO} / 50$, rollo 106 , vol. 251 , fs. 102-103, y 6 de marzo de 1852 , despacho núm. $15, \mathrm{FO} / 50$, rollo 106 , vol. 251 , fs. 184-185. 


\section{El PAPEL DE Gran BrEtaña}

La pregunta que debemos formular aquí es: ¿tenía Inglaterra algún papel que jugar en este asunto entre vecinos? Sin dudarlo, Percy Doyle habría contestado que sí. Incluso antes de llegar a México, estaba enterado de los designios estaunidenses sobre el istmo de Tehuantepec y se proponía tomar providencias para frenarlos. ${ }^{25}$ Concedía al asunto gran importancia por tres razones: su posible efecto sobre el comercio inglés, la participación de súbditos británicos en la empresa y la creciente influencia de Estados Unidos sobre México.

El enviado fue enfático al tratar este último punto; como se vio arriba, estaba convencido de que los estadunidenses intentarían, por todos los medios, adueñarse de la región y sacar provecho a costa de México. ${ }^{26}$ El único remedio, a sus ojos, era que Gran Bretaña tomara cartas en el asunto, tarea nada fácil. Para empezar, Doyle llegó a México sin instrucciones respecto a la cuestión del paso transístmico; eso indica que el mismo no era un asunto prioritario para el gobierno británico. ${ }^{27}$ Años después, el ministro se veía obligado, con frecuencia, a presentar sus opinio-

\footnotetext{
${ }^{25}$ Doyle a Palmerston, Bermuda, 18 de noviembre de 1847 , despacho privado s.n., FO/50, rollo 89 , vol. 212 , fs. 191-195.

${ }^{26}$ Doyle a Palmerston, México, 24 de diciembre de 1847, despacho duplicado núm. 7 , FO/50, rollo 89 , vol. 212, f. 236.

${ }^{27}$ Doyle a Palmerston, Bermuda, 18 de noviembre de 1847 , despacho privado s.n., FO/50, rollo 89 , vol. 212, f. 194.
}

nes a título personal, por carecer de referencias oficiales en que basarlas. ${ }^{28}$

En realidad, las instrucciones que recibió Doyle fueron siempre lacónicas, mesuradas e inapelables: abstenerse, en lo posible, de intervenir; informar meticulosamente acerca de todos los acontecimientos; enviar noticias, copias y traducciones de cada documento a su alcance, y conservar todo por escrito; prestar sus buenos oficios a las partes en conflicto; estar alerta y seguir muy de cerca el asunto, velando, ante todo, por los intereses comerciales y políticos de Gran Bretaña. ${ }^{29}$

${ }^{28}$ Doyle a Palmerston, México, 4 de febrero de 1851, despacho núm. 13, FO/50, rollo 102 , vol. 243, f. 83 .

${ }^{29}$ Esto puede comprobarse en las breves anotaciones al margen de los despachos de Doyle, seguramente hechas por el secretario del ministro en turno, con el objeto de recordar el tenor al que serian redactadas las instrucciones subsecuentes. Véanse también [Palmerston] a Doyle, [Londres], 29 de enero de 1848 , borrador núm. [2], FO $/ 50$, rollo 91, vol. 218, fs. $5.6,31$ de agosto de 1848 , borrador núm. 38 , FO/50, rollo 91, vol. 218 , fs. $77-80 ; 1$ de mayo de 1850 , borrador núm. 14, $\mathrm{FO} / 50$, rollo 100 , vol. 235 , fs. $32-33 ; 27$ de diciembre de 1850 , borrador núm. 26, FO/50, rollo 100 , vol. 235 , fs. 101-104; 31 de marzo de 1851, borrador núm. 13, FO $/ 50$, rollo 102 , vol. 242 , fs. $27-28$; 16 de septiembre de 1851 , borrador núm. 43 , $\mathrm{FO} / 50$, rollo 102 , vol. 242 , fs. $87-89 ; 1$ de noviembre de 1851 , borrador separado s.n., FO/ 50 , rollo 102 , vol. 242 , fs. $113-114 ;$ y 25 de junio de 1852, borrador núm. 20, FO/50, rollo 106, vol. 250, fs. 46-47; Malmesbury a Doyle, [Londres], 14 de enero de 1853 , borrador núm. 3 , FO/50, rollo 110 , vol. 257 , fs. $5-6$; Clarendon a Doyle, [Londres], 22 de abril de 1853, borrador núm. 12, FO/50, rollo 110 , vol. 257 , fs. 53$56 ; 27$ de mayo de 1853 , borrador núm. 17, FO/50, rollo 110 , vol. 257 , fs. $66-67$, s.f. Irespuesta al despacho núm. 41, del 2 de abril de 1853], FO/50, rollo 110, vol. 259, fs. 98-99; 9 de 
A juzgar por sus despachos -en especial los primeros-, Doyle estaba no sólo preocupado por cumplir con su deber sino incluso entusiasmado por la posibilidad de que su gobierno le diera luz verde para participar más activamente en el asunto de Tehuantepec; sólo podemos imaginar el lucimiento que ello habría aportado a su gestión.

Doyle se encontraba, como muchos otros diplomáticos en diversas épocas y lugares, en una postura difícil: debía conciliar las demandas y urgencias de los políticos mexicanos -más aún, vivía en carne propia la difícil realidad mexicana- con la línea, casi siempre restrictiva, que le señalaba el Foreign Office. A ello se añadía su convencimiento personal acerca de la relevancia de la cuestión que aquí tratamos, y que de seguro lo impulsaría a delinear elementos de política exterior, más allá de su cometido, con la esperanza de estimular el interés por un asunto cuyas oportunidades y problemas no eran, según él, bien percibidos por su gobierno. Pero al actuar, Doyle siempre acató las exigencias de sus superiores, conformándose con representar un papel modesto en el drama, para él incuestionable, del paso interoceánico por el istmo de Tehuantepec.

Es necesario resaltar las peculiares condiciones de la república en que prestaba sus servicios. El diplomático juzgaba a México un país no sólo enrevesa-

mayo de 1854 , borrador núm. $48, \mathrm{FO} / 50$, rollo 113, vol. 265 , fs. $105-106,1$ de agosto de 1854 , borrador núm. $80, \mathrm{FO} / 50$, rollo 113 , vol. 265 , fs. $174-175 ; 31$ de octubre de 1854 , borrador núm. 99, FO $/ 50$, rollo 113 , vol. 265 , fs. 225-229, y 1 de marzo de 1855, borrador núm. 13, FO/50, rollo 117 , vol. 275 , fs. $35-36$. do sino, de hecho, colocado en un callejón sin salida. Luchar contra Estados Unidos le sería imposible sin el apoyo europeo, concretamente británico. En varias ocasiones Doyle alertó a su gobierno sobre el grave peligro que corría México de desintegrarse y sucumbir merced a la presión combinada de sus dificultades internas, el nefasto ascendiente de su vecino del norte y el posible abandono de Europa. ${ }^{30}$

Pero las grandes potencias del viejo continente -Inglaterra sobre todo- rehuían el compromiso de brindar ayuda militar y exponerse a conflictos abier. tos con Estados Unidos. ${ }^{31}$ Por un lado peligraba la existencia misma de México; por el otro, se comprometía la posibilidad de una vía interoceánica $e n$ Tehuantepec, si bien esta última parecía remota a los ojos de Doyle. ${ }^{32}$

${ }^{30}$ Doyle a Palmerston, México, 4 de febrero de 1851, despacho confidencial núm. 14, FO/ 50 , rollo 103 , vol. 243 , fs. $100-110$, y 4 de noviembre de 1851, despacho núm. 95, FO/50, rollo 104, vol. 246, fs. 181-186; Doyle a Malmesbury, México, 2 de septiembre de 1852, despacho núm. 65, FO/50, rollo 107 , vol. 253, fs. 175-180; Doyle a Clarendon, México, 3 de diciembre de 1853, despacho secreto núm. 117 , FO/50, rollo 111, vol. 261, fs. 267-286.

${ }^{31}$ Brauer, "United", 1988; Platt, Finance, 1971

32 Una de las razones para ello era la existencia de otros proyectos de pasos interoceánicos -Panamá y Nicaragua- más viables y menos arriesgados desde el punto de vista inglés. Otra el convencimiento de Doyle respecto al peso de los especuladores en el asunto: sospechaba que algunas propuestas para la vía eran sólo fachadas de intereses mucho menos altruistas. Véanse G. R. Porter a Eddisbury, Londres, 12 de agosto de $1848, \mathrm{FO} / 50$, rollo 95 , vol. 225 , fs 201-206; Doyle a Palmerston, México, 16 de marzo de 1850 , despacho núm. $26, \mathrm{FO} / 50$, rollo 100, vol, 235, f. 173; Palmerston [a Doyle, 
En su discurso oficial, México importaba sobre todas las cosas; los hechos demostraron lo contrario. Pese a las esperanzas de más de un dirigente mexicano de que la Gran Bretaña se preocuparía por el asunto del istmo y detendría la amenaza estaunidense, la política del Foreign Office y la línea de conducta seguida por Doyle pueden resumirse de la siguiente manera: México tendría que defender por sí mismo su independencia y su integridad como país, sin depender del socorro europeo que, por otra parte, no era factible que, en las circunstancias del caso, otorgara ninguna nación sensata. ${ }^{33}$

Lo interesante es que los estadunidenses no parecían muy conscientes de esto y temían el momento en que

Londres], 20 de septiembre de 1850, FO/50, rollo 100, vol. 237, f. 74; Doyle a Palmerston, México, 4 de abril de 1851, despacho núm. 50, FO/50, rollo 103 , vol. 143 , f. $241 ; 4$ de enero de 1852 , despacho núm. 5 , FO/50, rollo 106 , vol. 251, fs. 54-55, y 4 de febrero de 1852, despacho núm. 7, FO/ 50 , rollo 106, vol. 251, f. 105; Doyle a Malmesbury, México, 2 de septiembre de 1852, despacho núm. 65 , FO/50, rollo 107 , vol. 253, f. 176; Doyle a Russell, México, 4 de marzo de 1853 , despacho núm. $34, \mathrm{FO} / 50$, rollo 110 , vol. 259 , fs. 22-24, y 2 de abril de 1853, despacho núm. 41 , FO/50, rollo 110 , vol. 259 , f. 94 ; Foreign Office, "Memorándum" sobre la comunicación interoceánica vía el istmo de Tehuantepec", [Londres], [i?] de abril de 1853, FO/50, rollo 111, vol. 259, fs. 275-279; Doyle a Clarendon, México, 3 de diciembre de 1853, despacho núm. 114, $\mathrm{FO} / 50$, rollo 111 , vol. 261, f. 242; [Clarendon] a Doyle, [Londres], 1 de marzo de 1855 , borrador núm. $13, \mathrm{FO} / 50$, rollo 117, vol. 275, f. 36; Doyle a Clarendon, México, 7 de febrero de 1855, despacho núm. 20, FO/50, rollo 118, vol. 276, fs. 178-179.

${ }^{33}$ Doyle a Clarendon, México, 3 de diciembre de 1853, despacho secreto núm. $117, \mathrm{FO} /$ 50, rollo 111, vol. 261, f. 286. los británicos intervendrían activamente en su contra, como se percibe en la correspondencia de sus enviados. De algún modo, puede afirmarse que la acción o inacción británica en su política exterior hacia México fue un espantajo que en efecto frenó a Estados Unidos, merced a la ansiedad y los recelos que producía en ellos.

\section{PARADOJAS DE LA DIPLOMACIA}

Desde 1850 Doyle sabía que, por el artículo $8^{\circ}$ del Tratado Clayton-Bulwer, su país podía, en cualquier momento, reclamar a Estados Unidos la intervención en un protectorado conjunto sobre el istmo de Tehuantepec; pero, conocedor de la postura de Gran Bretaña al respecto, se limitó a recordarlo a sus superiores cuando fue el caso, guardándose bien de no darlo a enten. der a nadie en México. ${ }^{34}$

Seis años después, Percy Doyle se encontraba en Europa intentando restablecer su salud con las aguas termales del sur de Francia. No es probable que la situación de México le quitase el sueño, pero lo cierto es que era motivo de serias reflexiones para él. Alcanzado por los rumores acerca de movimientos de tropas estaunidenses en el istmo, discurría de este modo:

Si ellos, una vez establecidos alli por la fuerza, pueden marchar sobre la capital en cinco o seis días [...] teniendo en su poder toda la franja del río Bravo del

${ }^{34}$ Doyle a Clarendon, México, 3 de julio de 1854 , despacho núm. $71, \mathrm{FO} / 50$, rollo 114 , vol. 268 , f. 9 . 
Norte, atraparán a México en una red perfecta. $^{35}$

Ahora sabemos que no fue así; la última porción de territorio mexicano que cayó en manos de Estados Unidos fue La Mesilla, en 1853, cuando el ministro británico aún seguía en su puesto. Quizá el último escrito que conocemos de Doyle sobre el asunto de Tehuantepec fue el postrer reflejo de sus convicciones personales y su afán de protagonismo, que cedieron siempre el lugar al diplomático cauteloso y leal a su país. Cabe preguntarse hasta qué punto, incluso desde otro continente, sus opiniones sirvieron para reforzar la paranoia mexicana y estadunidense.

A modo de conclusión diremos que la diplomacia británica, representada por Doyle, en lo relativo a las negociaciones del paso transístmico durante el periodo estudiado se limitó a "neutralizar" el vasto ascendiente de Estados Unidos sobre México, ${ }^{36}$ matizando su actuación con un discurso de buena voluntad y amistad.$^{37} \mathrm{Al}$ mismo tiempo, investigaciones como la presente arrojan nuevas luces sobre la compleja relación México-Estados Unidos. Esto es especialmente cierto por cuanto la sitúan en un contexto más amplio y completo, desde el punto de vista de un tercer actor, no objetivo ni altruis-

${ }^{35}$ Doyle a [Edmund] Hammond, Aix les Baines, 22 de agosto de 1856 , carta privada, FO/50, rollo 125 , vol. 294 , fs. 93-94.

${ }^{36}$ Clarendon a Doyle, [Londres], 31 de octubre de 1854 , borrador núm. $99, \mathrm{FO} / 50$, rollo 113, vol. 265, f. 225.

${ }^{37}$ Doyle a Palmerston, México, 4 de noviembre de 1851, despacho núm. $95, \mathrm{FO} / 50$, rollo 104, vol. 246 , fs. 185-186. ta, pero sí enterado e influyente. En cuanto al papel de Percy Doyle dentro de la política exterior británica hacia México, queda por averiguar qué tan representativo fue, en términos generales. Para ello hace falta continuar con el estudio de los materiales del Foreign Office, de cuya riqueza esperamos haber dado muestra en este ensayo.

\section{ARCHIVOS}

-FO Great Britain Public Record Office.

\section{BIBLIOGRAFÍA}

-Bourne, Kenneth, Britain and the balance of power in North America 1815-1908, University of California Press, Berkeley, 1967.

-Brauer, Kinley J., "The United States and british imperial expansion, 1815-60" en Diplomatic History, núm. 1, vol. 12, pp. 19-37.

-Clarke, John, British diplomacy and foreign policy 1782-1865. The national interest, Unwin Hyman, Londres, 1989.

-Gallagher, John y Ronald Robinson, "The imperialism of free trade", en The Economic History Review, núm. 1, vol. v, pp. 1-15.

-Jones, Wilbur Devereaux, The american problem in british diplomacy, 1841-1861, University of Georgia Press, Athens, 1974.

-Kennedy, Paul, The realities behind diplomacy: background influences on british external policy, 1865-1980, George Allen \& Unwin, Londres, 1981.

-Mayo, John, "The impatient lion: Britain's 'official mind' and Latin America in the 1850's", Ibero-Amerikanisches Archiv, nueva serie, año 9, vol. 2, pp. 197-223.

-Platt, D. C. M, Finance, trade, and politics in british foreign policy 1815-1914, Clarendon Press, Oxford, 1971. 